\title{
Vegetative and Adaptive Traits Predict Different Outcomes for Restoration Using Hybrids
}

\begin{abstract}
Philip A. Crystal1,2, Nathanael I. Lichti1 ${ }^{1}$ Keith E. Woeste ${ }^{1,3}$ and Douglass F. Jacobs ${ }^{1 *}$
1 Hardwood Tree Improvement and Regeneration Center, Department of Forestry and Natural Resources, Purdue University, West Lafayette, IN, USA, ${ }^{2}$ Department of Biology, Colby College, Waterville, ME, USA, ${ }^{3}$ Hardwood Tree Improvement and Regeneration Center, Northern Research Station, USDA Forest Service, West Lafayette, IN, USA
\end{abstract}

Hybridization has been implicated as a driver of speciation, extinction, and invasiveness, but can also provide resistant breeding stock following epidemics. However, evaluating the appropriateness of hybrids for use in restoration programs is difficult. Past the F1 generation, the proportion of a progenitor's genome can vary widely, as can the combinations of parental genomes. Detailed genetic analysis can reveal this information, but cannot expose phenotypic alterations due to heterosis, transgressive traits, or changes in metabolism or development. In addition, because evolution is often driven by extreme individuals, decisions based on phenotypic averages of hybrid classes may have unintended results. We demonstrate a strategy to evaluate hybrids for use in restoration by visualizing hybrid phenotypes across selected groups of traits relative to both progenitor species. Specifically, we used discriminant analysis to differentiate among butternut (Juglans cinerea L.), black walnut (J. nigra L.), and Japanese walnut (J. ailantifolia Carr. var. cordiformis) using vegetative characters and then with functional adaptive traits associated with seedling performance. When projected onto the progenitor trait space, naturally occurring hybrids $(\mathrm{J} . \times$ bixbyi Rehd.) between butternut and Japanese walnut showed introgression toward Japanese walnut at vegetative characters but exhibited a hybrid swarm at functional traits. Both results indicate that hybrids have morphological and ecological phenotypes that distinguish them from butternut, demonstrating a lack of ecological equivalency that should not be carried into restoration breeding efforts. Despite these discrepancies, some hybrids were projected into the space occupied by butternut seedlings' 95\% confidence ellipse, signifying that some hybrids were similar at the measured traits. Determining how to consistently identify these individuals is imperative for future breeding and species restoration efforts involving hybrids. Discriminant analysis provides a useful technique to visualize past selection mechanisms and current variation in hybrid populations, especially when key ecological traits that distinguish progenitors are unknown. Furthermore, discriminant analysis affords a tool to assess ecological equivalency of hybrid populations and breeding program efforts to select for certain traits and monitor the amount of variability of those traits, relative to progenitors.

Keywords: discriminant analysis, ecological equivalency, ecophysiology, forest restoration, habitat differentiation, hybridization, introgression, Juglandaceae 


\section{INTRODUCTION}

Naturally occurring hybridization between native and exotic species can dilute native gene pools and result in extinction, especially of rare species (Levin et al., 1996; Rhymer and Simberloff, 1996). Hybridization has also been implicated in development of invasiveness, as increased genetic diversity is correlated with adaptation to environmental variation (Ellstrand and Schierenbeck, 2006). Conversely, hybridization has been used to introduce anthropogenically desired traits for thousands of years (Rieseberg and Carney, 1998), and naturally occurring hybrids between susceptible, native taxa and resistant, exotic taxa may present a means to introduce resistance to exotic pests and pathogens in vulnerable species of concern (Michler et al., 2006).

Given that hybrids exist, their functionality influences the degree to which they threaten native populations and is the major factor in determining their effects on ecosystem integrity. Depending on the interplay between the fitness contributions of genetic material from both progenitors relative to the selection environment, hybrids may (1) introgress toward one of the progenitor species or (2) persist as an intermediate group, as is the case with most natural hybrid zones (Rhymer and Simberloff, 1996; Rieseberg and Carney, 1998, Campbell and Waser, 2001; Kimball et al., 2008). Alternatively, novel gene combinations or interactions among genetic contributions with selection (or polyploidy) may allow hybrids to (3) undergo speciation. Unless selection reduces genetic variability, hybrids may also (4) proliferate into a hybrid swarm characterized by high phenotypic variability among individuals with extremely diverse genotypes (Rhymer and Simberloff, 1996; Rieseberg and Carney, 1998, Soltis and Soltis, 2009). The actual trajectory taken by a particular hybrid population also depends on the demography and mating system of its progenitors. Under some circumstances stochastic breeding has the potential to swamp out fitness effects (Rhymer and Simberloff, 1996). In such cases, hybrid populations can present as trajectories 1,2 , or 4 .

Identifying which trajectory a hybrid population is currently on would provide important information to evaluate how serious a threat hybridization poses to rare species (Levin et al., 1996; Rhymer and Simberloff, 1996) and overall ecosystem health. Assessing the hybrid trajectory is therefore critical to the study and management of hybridizing populations, yet is difficult to accomplish using genetic analysis alone. The percent admixture (Boecklen and Howard, 1997), class (Anderson and Thompson, 2002), or entire sequence of a hybrid individual does little to reveal heterosis (hybrid vigor) and other non-additive genetic effects (Chen, 2010). Genetic data also reveal little regarding how differences in physiology and metabolism would affect secondary metabolite production (Cheng et al., 2011) or transgressive phenotypes (Rieseberg and Carney, 1998).

Physical studies can reveal non-additive phenotypic effects, but are complicated by the variability associated with hybridization. Typically, such studies group hybrids by class and then regress the performance of different classes against their mean scores for one or several variables (Diskin et al., 2006; Crystal and Jacobs, 2014). Cheng et al. (2011) demonstrate in the context of herbivore resistance, that for any given trait, hybrid phenotypes can exceed, be intermediate to, equivalent to, or below one or both progenitors, and that the proportion of hybrid individuals expressing these trait levels varies among hybrid generations: F1, F2, BC1F1. As such, grouping hybrids by families (which may contain various hybrid classes depending on paternity, recombination, and independent assortment) or by generation for statistical analysis based on class-level trait averages is not particularly meaningful. Furthermore, the average performance of an entire class is relatively unimportant as natural selection acts at the individual level. Even in a class with poor overall fitness, natural selection may ensure that a few exceptional individuals proliferate, as in the classical examples of hybrid speciation in Helianthus and Iris (Arnold and Martin, 2010).

We present an application of multivariate discriminant analysis (Legendre and Legendre, 2003) to identify the current trajectory of a pool of hybrids through visualization of individual hybrids in the context of the progenitors' traitspace. Discriminant analysis is particularly useful for assessing hybrid phenotypic selection mechanisms because it determines which variables from a candidate set most effectively describe differences among groups (i.e., progenitor species). Assuming the variables selected are those that selection is operating on, the ecological implications of those differences can be interpreted based on the environment that hybrids might be deployed into. While discriminant analysis has been previously used for morphometric analysis of hybrid taxonomy (Mayer and Mesler, 1993; Burgess et al., 2005, Barbour et al., 2007), it has not been used to investigate variation in functional traits that provide little a priori information on taxonomic status, but do pertain more directly to individual fitness (e.g., biomass or leaf area in plants; innate behaviors, pheromone production, or body mass in animals). The ability to simultaneously evaluate hybrids at multiple, often correlated traits is especially important, as fitness is not defined by a single character or by appearance per se, but rather by the interplay among traits that allow continued growth, survival, and most importantly, contributions to future generations.

In the context of hybridization between progenitors with distinct phenotypes, and assuming that genetic contributions are equal and that the environment is constant, the overall hybrid population would be expected to express some derivation of four basic trajectories (Figure 1). Directional selection toward one progenitor would result in distinct clustering of hybrids from an intermediate point between progenitors to the progenitor with greater fitness (Figure 1A). If both progenitors contribute equally to fitness (or if hybrids have greater fitness in an intermediate environment) the hybrid cluster will be maintained intermediate to progenitor clusters (Figure 1B). If hybrid speciation has occurred, the cluster will also be distinct, but may occupy a separate area of the parameter space (Figure 1C). Finally, if limited or no selection has occurred, or if F1 hybrid fitness facilitates the establishment of future hybrid generations (Drake, 2006), hybrids will not cluster out at all and will occupy up to the full parameter space between progenitor clusters (Figure 1D). They may also occupy novel trait spaces. In each instance, the size and shape of the hybrid cluster will depend upon the 

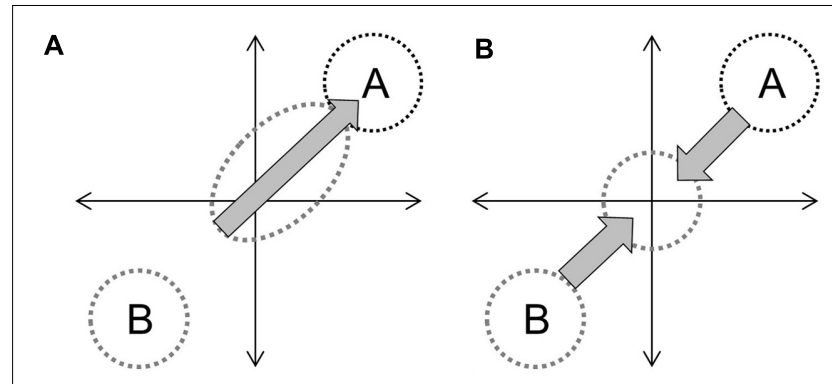

C
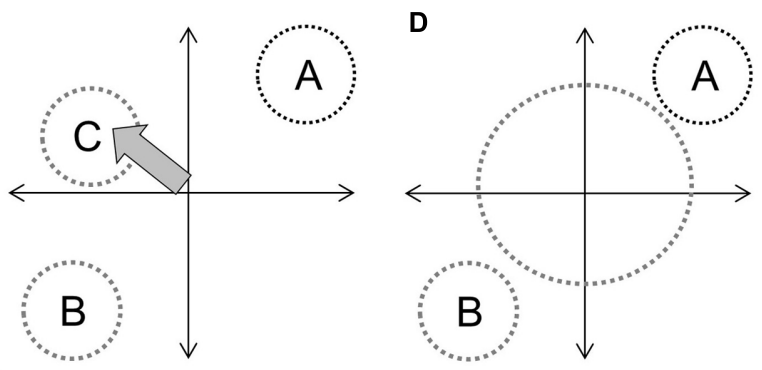

FIGURE 1 | Diagrammatic examples of four hybrid trajectories on an undefined parameter space representing combinations of functional adaptive traits: directional introgression (A), maintenance as an intermediate group (B), speciation (C), and the hybrid swarm effect (D), which operates under limited or no selection. Circle size indicates overall variability and labels denote defined species. Gray arrows indicate selection, with arrow size representing effect size.

strength of the fitness component and the strength and direction of selection. The demography of progenitor populations, the number of hybrid generations in coexistence and their fecundity can mask selection effects (Figure 2).

To illustrate this approach to hybrid assessment, the trajectory of naturally occurring hybrids (Juglans $\times$ bixbyi Rehd.), between butternut (J. cinerea L.) and heartnut (J. ailantifolia Carr. var. cordiformis) is examined using suites of qualitative vegetative descriptors and quantitative functional adaptive traits drawn from the literature. Black walnut (J. nigra) was included as an outgroup to expand the trait combination space and ensure a two-dimensional ordination. Results from both trait suites are discussed in the context of the potential ecological equivalence of $J . \times$ bixbyi to butternut for conservation.

\section{MATERIALS AND METHODS}

\section{Study Taxa}

Naturally occurring hybrids between butternut and heartnut present an ideal system to explore the use of discriminant analysis on adaptive trait variation. Heartnuts are a horticultural variety of Japanese walnut. Butternut and Japanese walnut are heterodichogamous members of the Juglandaceae, subsection Cardiocaryon (Stout, 1928; Fjellstrom and Parfitt, 1994, Kimura et al., 2003). Japanese walnut was introduced to North America in the late 1800s (Woeste and Pijut, 2009) and evidence of hybridization was first reported in 1916 (Bixby, 1919). Thus,
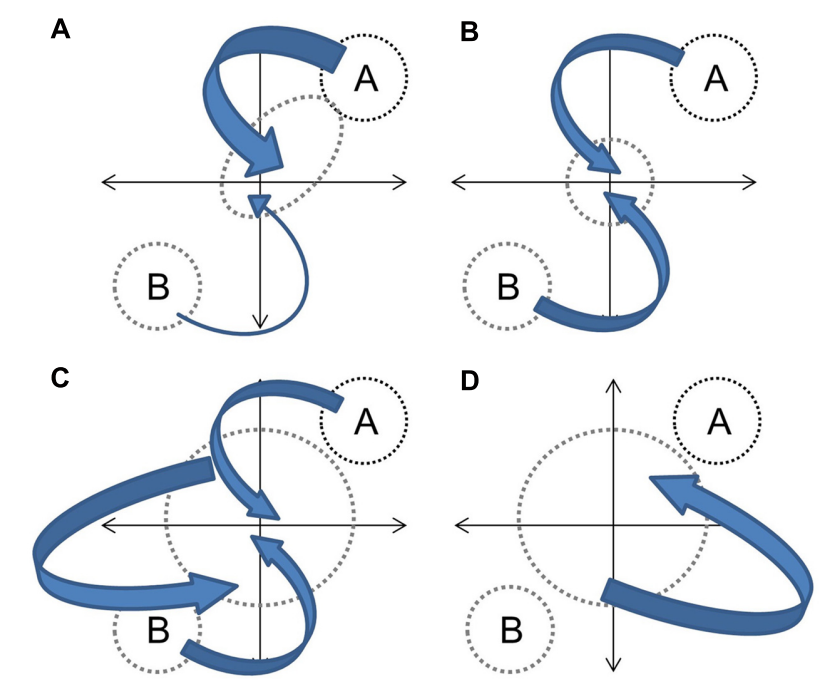

FIGURE 2 | Demography effects on hybrid phenotypes. Independent of selection, large contributions of species A relative to species B to future generations would skew the hybrids toward species A (A). Equal contributions between species $A$ and $B$ to future generations would pull the hybrid pool equally in both directions (B). Breeding among hybrid generations and parental species would increase variability with some directionality toward progenitors (C). Breeding solely among hybrids would increase variability independent of progenitor phenotypes (D). Arrow size indicates size of genetic contribution.

based upon the maturation age of butternut (20 years) and Japanese walnut (10 years), it is likely that several generations of hybridization have taken place over the last century (Bonner, 2008). Hoban et al. (2009) found evidence for the existence of F1, F2, and backcross hybrids from range-wide analysis. Hybrids might be used as a source of genes for resistance to butternut canker disease caused by the suspected exotic pathogen (Furnier et al., 1999), Ophiognomonia clavigignentijuglandacearum (Michler et al., 2006), which has decimated butternut populations (Ostry et al., 1994). However, Crystal and Jacobs (2014) found discrepancies between hybrids and both progenitors in terms of tolerance to flooding and drought. The extent to which the deployment of hybrids would be a practical or ecologically sensible method to address the demographic collapse of butternut is therefore unclear.

\section{Vegetative Characters and Functional Adaptive Traits}

All four taxa were characterized at 33 vegetative morphological characters and functional adaptive traits (Table 1). The majority of the vegetative characters were taken from the Descriptors for Walnut (Juglans spp.) (IJD: IPGRI, 1994): leaf color, margin, and shape; rachis color and pubescence; average number of leaflets per leaf; and stem pubescence. To ensure distinction between J. cinerea and J. ailantifolia, three traits were chosen from Farlee et al. (2010): lenticel shape, lenticel density, and leaf scar notching. Lenticel density was determined quantitatively in a 1$\mathrm{cm}^{2}$ area, between the fourth and fifth node from the shoot apex. 
Several other characteristics: initial shoot color and pubescence, leaf texture (glabrous, rough, or scabrous), and rachis texture (viscid or not viscid) were also assessed based on their potential to serve as vegetative descriptors or because they appeared to vary among seedlings of the taxa grown in the greenhouse.

The majority of functional adaptive traits were associated with seedling survival or quality assessment (Wilson and Jacobs, 2006; Grossnickle, 2012): height, root collar diameter, root volume, SPAD chlorophyll content, and dry biomass ratios of root to shoot. Height was assessed from soil medium to shoot apex. Root collar diameter was averaged from two perpendicular measurements at soil medium. Root volume was taken according to the volumetric method (Burdett, 1979) and plant material for dry biomass ratios was dried to a constant mass at $60^{\circ} \mathrm{C}$. Other measures more associated with habitat type were also assessed (Table 1). Photosynthetic rate and transpiration were obtained on 23 and 24 August 2012 using a LI-6400 portable photosynthesis system fitted with a 640002B LED light source. The LI-6400 was operated under default settings with $\mathrm{CO}_{2}, \mathrm{PAR}$, and temperature set to $400 \mathrm{ppm} \mathrm{CO}_{2}$, $1300 \mu \mathrm{mol} \mathrm{m} \mathrm{m}^{-2} \mathrm{~s}^{-1} \mathrm{PAR}$, and $25.0^{\circ} \mathrm{C} . \mathrm{CO}_{2}$ and PAR were set high to exceed differential capabilities by species. Relative humidity in the reference chamber was maintained at 44.4$55.5 \%$. Measurements were taken from 1100 to $1700 \mathrm{~h}$ as previous measurements on a subset of seedlings found no variation in photosynthetic rate from sun-up to sun-down (data not shown). Measures were logged after $A$ had plateaued for at least $30 \mathrm{~s}$.

\section{Discriminant Analysis}

In discriminant analysis, each sample (individual) is assigned to a predefined group, in this case a progenitor species or an outgroup. Variables are then analyzed for differences among pre-defined groups and eigenvectors (eigenvector if $n=2)$ that maximize the among group variance are generated, with the constraints that each eigenvector must be a linear combination of the sample traits, and that all eigenvectors must be orthogonal to each other. The first step functions similarly to a multivariate analysis of variance and the second is similar to principle correspondence analysis (Legendre and Legendre, 2003). Discriminant analyses were performed using the lda function in the MASS package in R (Venables and Ripley, 2002; R Core Team, 2012).

To determine the hybrid trajectory, a discriminant analysis was first performed on open-pollinated individuals of the three walnut species (J. cinerea, J. ailantifolia, and J. nigra) using the vegetative or adaptive trait suite. Data from these individuals were then plotted on the discriminant axes and each species cluster was enclosed within a 95\% confidence ellipse (confidenceEllipse function in the car package: Fox and Weisberg, 2011). Data from sampled hybrids were then projected onto the species biplot to visualize their location on the discriminant axes (Barbour et al., 2007).

Prior to discriminant analysis, quantitative variables were visually inspected for normality using histograms. Only shoot:root dry mass required transformation $(\sqrt{ }[$ shoot:root +1$])$. Variables were then standardized to $z$-scores to place traits on
TABLE 1 | Vegetative characters and functional adaptive traits with transformations used in analysis.

\begin{tabular}{ll}
\hline Vegetative characters & Adaptive traits* \\
\hline Initial shoot color & ${ }^{3,4}$ Final height \\
Initial shoot pubescence & ${ }^{3,4}$ Final root collar diameter \\
${ }^{1}$ Leaf shape & Average leaf length \\
${ }^{1}$ Leaf margin & ${ }^{5}$ Average leaf area \\
${ }^{1}$ Leaf color & ${ }^{6}$ Average crown area \\
Leaf texture & Total leaf number \\
${ }^{1}$ Average number of & ${ }^{5}$ Estimated total leaf area \\
leaflets leaf ${ }^{-1 *}$ & \\
${ }^{1}$ Rachis color & Estimated total leaf area stem ${ }^{-1}$ \\
${ }^{1}$ Rachis pubescence* & SPAD chlorophyll content \\
Rachis texture & ${ }^{5}$ Specific leaf area $\left(\mathrm{SLA}^{*} \mathrm{~m}^{2} \mathrm{~g}^{-1}\right)$ \\
${ }^{1}$ Stem pubescence & Photosynthesis $\left(\mu \mathrm{mol} \mathrm{CO} \mathrm{g}^{-1} \mathrm{~s}^{-1}\right)$ \\
${ }^{2}$ Lenticel shape & SLA correlated photosynthesis $\left(\mu \mathrm{mol} \mathrm{CO}_{2} \mathrm{~m}^{-2} \mathrm{~s}^{-1}\right)$ \\
${ }^{2}$ Lenticel density* & Transpiration (mmol $\left.\mathrm{H}_{2} \mathrm{O} \mathrm{m}^{-2} \mathrm{~s}^{-1}\right)$ \\
${ }^{2}$ Leaf scar notched & Water use efficiency $\left(\mathrm{umol} \mathrm{CO}_{2} \mathrm{mmol}^{-1} \mathrm{H}_{2} \mathrm{O}\right)$ \\
Number of nodes* & ${ }^{3,4}$ Root volume \\
& Foliar:rachis dry mass \\
& 3,4 Total dry mass \\
& 3,4 shoot:root dry mass \\
&
\end{tabular}

Asterisks (*) denote quantitative variables. ${ }^{1}$ IPGRI (1994), ${ }^{2}$ Farlee et al. (2010), ${ }^{3}$ Wilson and Jacobs (2006), ${ }^{4}$ Grossnickle (2012), ${ }^{5}$ Cornelissen et al. (2003), ${ }^{6}$ Gauthier et al. (2013)

a single common scale. Individuals with missing trait values ( $J$. nigra $=2, J . \times$ bixbyi $=4)$ were excluded from analysis. Five $J . \times$ bixbyi individuals included in the adaptive trait projection were excluded from the vegetative projection. Due to transgressive rachis pubescence in hybrids, this trait was encoded as a quantitative variable in the vegetative character analysis. As traits in both analyses were carefully chosen a priori, variables were not assessed for differences among pure species using separate analysis of variance tests prior to running the discriminant function (Legendre and Legendre, 2003).

\section{Plant Material and Planting}

Seeds from $J$. cinerea, J. nigra, and $J . \times$ bixbyi were collected in fall, 2011 from provenances archived at research plantations and from naturally occurring trees throughout Indiana, USA (Table 2). J. ailantifolia var. cordiformis seed from six of the most common cultivars (Table 2) was obtained from Grimo Nut Nursery (Ontario, Canada, 43 $15^{\prime} \mathrm{N}, 79^{\circ} 09^{\prime} \mathrm{W}$ ). After collection, seeds were hulled, washed, and allowed to air dry. On December 19, 2012 (J. cinerea, J. nigra, and J. $\times$ bixbyi) and December 20, 2012 (J. ailantifolia) seeds were rinsed in cold water, packed into bags filled with moistened, sifted peat moss by family, and cold stored at $5^{\circ} \mathrm{C}$ at the Purdue University Wright Forestry Center (West Lafayette, IN, USA, $\left(\begin{array}{ll}40^{\circ} & 25^{\prime}\end{array}\right.$ $\left.\mathrm{N}, 87^{\circ} 02^{\prime} \mathrm{W}\right)$. For measurement of seed characteristics (data not shown), on April 18, 2012 all seeds were unpacked, rinsed in cold water to remove excess peat, and returned to cold storage.

To account for both interfamilial and species variation in seedling emergence time and the subsequent effects on growth 
TABLE 2 | Family, provenance, and number of sample replicates for the four taxa included in the experiment: Juglans ailantifolia Carr. var. cordiformis (family $=6$ : total $n=21$ ), J. cinerea L. (8: 37), J. nigra L. (11: 39), and J. x bixbyi Rehd. (16: 79).

\begin{tabular}{|c|c|c|c|}
\hline Taxon & Family & Provenance & $n^{1}$ \\
\hline \multirow{6}{*}{$\begin{array}{l}\text { Juglans ailantifolia Carr. } \\
\text { var. cordiformis }\end{array}$} & Bates & - & 4 \\
\hline & Simcoe 8-2 & - & 6 \\
\hline & Fodermaier & - & 5 \\
\hline & Campbell CW1 & - & 3 \\
\hline & Imshu & - & 1 \\
\hline & Locket & - & 2 \\
\hline \multirow[t]{9}{*}{ Juglans cinerea L. } & 712 & Whitewater, WI, USA & 3 \\
\hline & 717 & Whitewater, WI, USA & 2 \\
\hline & 719 & Whitewater, WI, USA & 10 \\
\hline & 724 & Whitewater, WI, USA & 5 \\
\hline & 741 & Whitewater, WI, USA & 5 \\
\hline & 766 & Whitewater, WI, USA & 2 \\
\hline & 784 & Plymouth, IN, USA & 7 \\
\hline & 927 & Laona, WI, USA & 1 \\
\hline & 1622 & Pembine, WI, USA & 2 \\
\hline \multirow[t]{11}{*}{ Juglans nigra L. } & 502 & $\mathrm{KS}$ & 4 \\
\hline & 504 & IA & 6 \\
\hline & 513 & $\mid A$ & 8 \\
\hline & 514 & KS & 1 \\
\hline & 516 & $\mathrm{KY}$ & 5 \\
\hline & 517 & $\mid \mathrm{A}$ & 6 \\
\hline & 520 & IA & 2 \\
\hline & 525 & IA & 2 \\
\hline & 527 & $\|$ & 1 \\
\hline & 528 & $\mathrm{IL}$ & 3 \\
\hline & 529 & Unknown & 1 \\
\hline \multirow[t]{15}{*}{ Juglans × bixbyi Rehd. } & 701 & Rochester, IN, USA & 2 \\
\hline & 735 & Sanford, ME, USA & 4 \\
\hline & 745 & Scotland, ON, Canada & 4 \\
\hline & 780 & Plymouth, IN, USA & 4 \\
\hline & 781 & Plymouth, IN, USA & 7 \\
\hline & 782 & Plymouth, IN, USA & 3 \\
\hline & 803 & Angola, IN, USA & 5 \\
\hline & 890 & Twinsburg, OH, USA & 8 \\
\hline & 1001 & Clermont, KY, USA & 2 \\
\hline & 1061 & West Lafayette, IN, USA & 9 \\
\hline & 1062 & Culver, IN, USA & 6 \\
\hline & 1064 & West Lafayette, IN, USA & 9 \\
\hline & 1065 & West Lafayette, IN, USA & 7 \\
\hline & 1066 & West Lafayette, IN, USA & 6 \\
\hline & 1093 & Augusta, MI, USA & 3 \\
\hline
\end{tabular}

${ }^{1}$ Half-sib individuals represented in each family.

(Seiwa, 2000), stratification was extended past the recommended 90-120 days for J. cinerea and J. nigra (Bonner, 2008) to 126 (J. cinerea, J. nigra, J. $\times$ bixbyi) and 125 (J. ailantifolia) days. To further minimize emergence time variation and avoid potting unviable seed, all material was pre-germinated following the methods of Woeste et al. (2011). Seeds were sown in flats containing Scotts Metro-Mix $560^{\circledR}$ with Coir (MM 560) growing media and placed in the greenhouse set to maintain $26.7 / 18.3^{\circ} \mathrm{C}$ (day/night) on April 23, 2012. Seeds were removed and re-sown, every 3 days to visualize emergence. Seeds with radicle emergence less than $5 \mathrm{~mm}$ were wrapped in wet burlap to prevent desiccation and returned to the cooler at $5^{\circ} \mathrm{C}$.

On May 22, 2012, seeds were planted as a completely randomized design into the top $7 \mathrm{~cm}$ of 9.63-L pots (TP818, Stuewe and Sons, Tangent, OR, USA), pre-filled with $3783.9 \pm 184.1 \mathrm{~g}$ of MM 560 mixed with $48.2 \mathrm{~g}$ of Osmocote Plus $^{\circledast}$ 15-9-12, 8-9 month controlled-release fertilizer. Pots were immediately watered twice to allow for soil settling and prevent seed desiccation. Emergence occurred from May 29 to June 2, 2012, after which, non-germinating seedlings were discarded. Until emergence, pots were lightly watered each day to ensure the top of the pot (and the seed) remained moist; watering then occurred every 2-3 days to maintain field capacity. On July 6 , 2012, chlorophyll mutants were also discarded. Seedlings were moved from benches to a cinderblock grid on the floor from July 28 to 29, 2012. Defoliation occurred from 15 to 21 September 2012, after which watering ceased. Plants were destructively harvested for biomass measurements and root volume on November 2, 2012. From May 22 to September 21, 2012, average temperature and relative humidity were $($ mean $\pm S D)$ : $25.7 \pm 6.1^{\circ} \mathrm{C}$ and $30.1 \pm 7.1 \%$.

\section{RESULTS}

Seedlings of J. ailantifolia, J. cinerea, and J. nigra were effectively differentiated by the eigenvectors generated from both the vegetative and adaptive discriminant analyses (Figures 3 and $\mathbf{4}$ ). The two eigenvectors for each analysis described essentially all of the variation in their respective datasets (proportion of trace: Table 3). Trait loadings were relatively high for two vegetative traits: initial shoot color and leaf texture (Table 3). No adaptive traits were exceptional at discriminating species, with total biomass describing the most variation across both linear discriminant analyses (LDAs, Table 3).

Seedlings of J. ailantifolia, J. cinerea, and J. nigra clustered tightly in the vegetative trait LDA (Figure 3A). There was no overlap among $95 \%$ confidence ellipses, and J. ailantifolia-J. cinerea were separated the least by the canonical discriminant functions, perhaps reflecting taxonomic proximity. The J. cinerea ellipse (Figure 3A) had the greatest dispersion overall, potentially reflecting larger genetic variation among sampled individuals relative to the other species. When hybrids were applied onto the parameter space, most individuals fell on a gradient between J. ailantifolia and J. cinerea ellipses (Figure 3B). Roughly $50 \%$ of the hybrids fell within the J. ailantifolia ellipse, with $21 \%$ in the $J$. cinerea ellipse, and $23.5 \%$ intermediate in a space not occupied by either progenitor species' ellipse (Table 4 ).

Clusters for J. ailantifolia, J. cinerea, and J. nigra based on functional adaptive traits were fairly distinct and reasonably well separated (Figure 4A). There was some overlap between J. cinerea and J. nigra ellipses, with both equivalent distances from the J. ailantifolia ellipse. Hybrids projected onto the parameter space were widely and relatively evenly dispersed (Figure $4 \mathrm{~B}$ ). The 
A

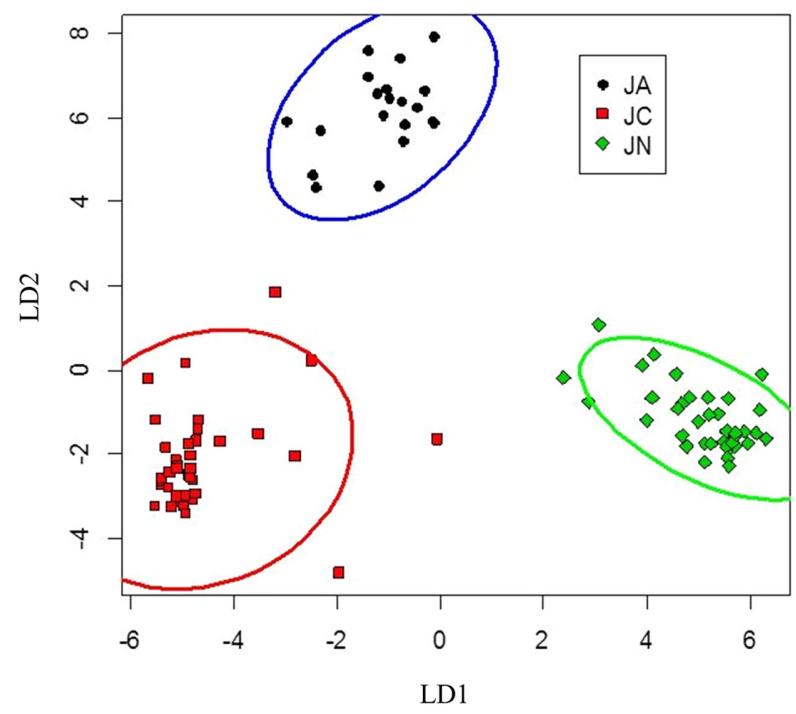

B

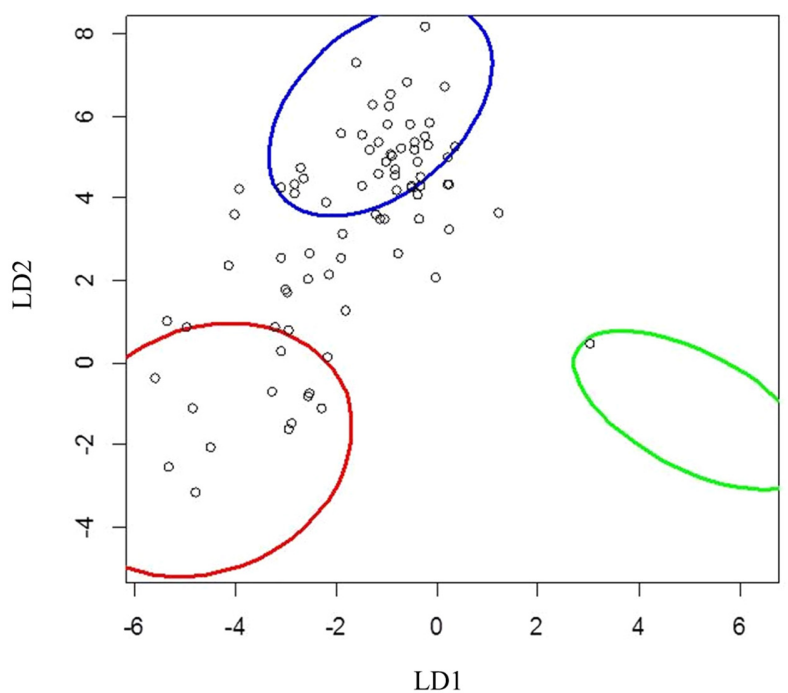

FIGURE 3 | Canonical discriminant analysis separating Juglans ailantifolia Carr. var. cordiformis (JA), J. cinerea L. (JC), and J. nigra L. (JN) based upon vegetative characteristics (A). J. $\times$ bixbyi Rehd. (JX) individuals (open circles) were applied to the parameter space using the discriminant function determined from (A). (B) Pure species are enclosed by 95\% confidence interval ellipses. LD1 and LD2 refer to the first and second discriminant axes, respectively.

A

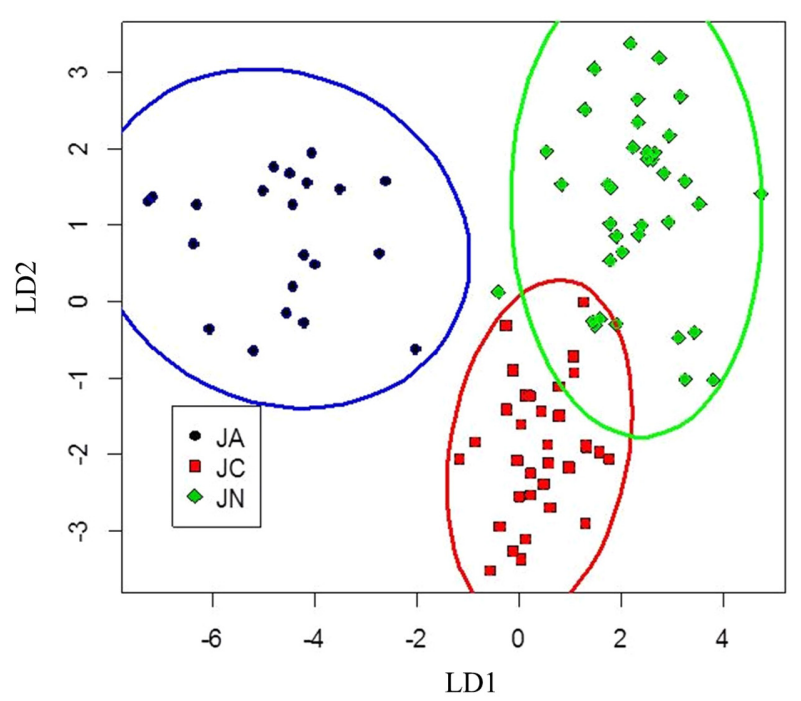

B

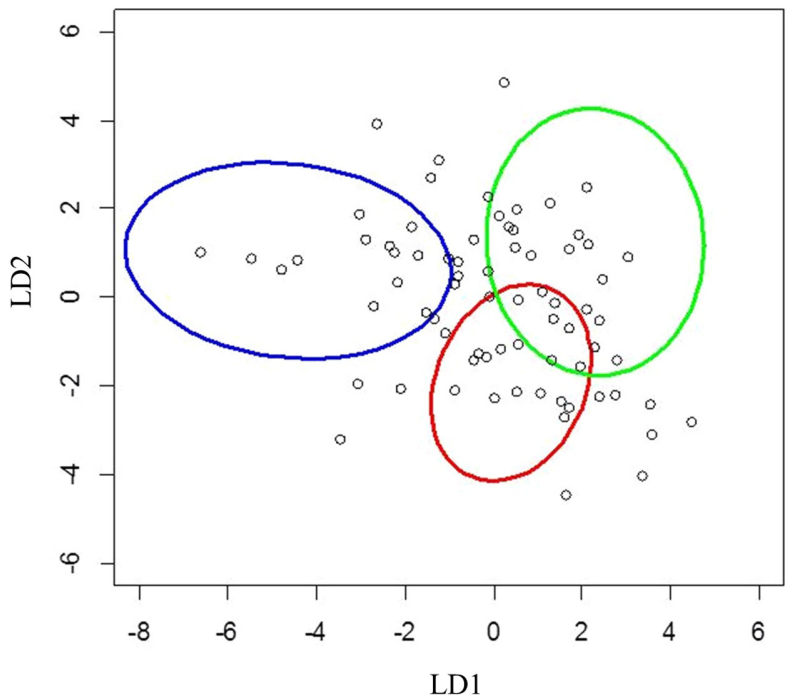

FIGURE 4 | Canonical discriminant analysis separating J. ailantifolia Carr. var. cordiformis, J. cinerea L., and J. nigra L. based upon functional adaptive traits (A). J. $\times$ bixbyi Rehd. individuals were applied to the parameter space as Figure $\mathbf{3}$ (B).

largest proportion $(36.6 \%)$ of hybrids fell within the J. nigra ellipse including the overlap with the $J$. cinerea ellipse. If the combined proportion of individuals occupying the overlap between the J. cinerea and J. nigra ellipses were excluded, most $23.3 \%$ of the total hybrids occupied the J. ailantifolia parameter space (Table 4). Only $16.4 \%$ (28.7\%, including J. cinerea/J. nigra overlap space) of hybrids fell within the J. cinerea ellipse. Furthermore, $17.8 \%$ of hybrids represented novel combinations of progenitor traits and fell outside the parameter space occupied by J. ailantifolia, J. cinerea, and J. nigra ellipses.

Hybrid projections in the vegetative and adaptive trait LDAs were not synonymous. Of the 73 hybrids remaining after exclusion of individuals with missing data points in the adaptive analysis, only $11(15.1 \%)$ fell within $J$. ailantifolia space and $4(5.5 \%)$ fell within $J$. cinerea space in both analyses. Halfsib progenies were fairly consistent in agreement across the 
TABLE 3 | Loading values for vegetative and adaptive traits as assigned by canonical discriminant analysis.

\begin{tabular}{|c|c|c|c|c|c|}
\hline Vegetative trait loadings ${ }^{1}$ & LD1 & LD2 & Adaptive trait loadings ${ }^{2}$ & LD1 & LD2 \\
\hline Average leaflet number & 0.056 & -0.231 & Height & 0.857 & -1.692 \\
\hline Number of nodes & 0.090 & 0.335 & Diameter & -0.994 & -1.380 \\
\hline Lenticel density & -0.099 & 0.014 & Average leaf length & -0.257 & 0.799 \\
\hline Rachis pubescence & 0.006 & 0.020 & Average crown area & 0.455 & -0.103 \\
\hline Initial shoot (IS) color intermediate & 0.097 & -1.037 & Leaf number & 1.073 & -0.276 \\
\hline IS color red & -2.309 & -4.228 & Est. total leaf area & -0.764 & -0.309 \\
\hline IS pubescence no & -0.651 & -1.372 & Leaf area stem $^{-1}$ & 0.481 & -0.501 \\
\hline IS pubescence intermediate & 0.009 & -1.139 & Average leaf area & 0.231 & -0.622 \\
\hline IS yes & 1.702 & -1.783 & ${ }^{1} \mathrm{SPAD}$ & 0.130 & -0.379 \\
\hline Leaf shape broad elliptic & 0.846 & -0.717 & Specific Leaf Area (SLA) & 1.026 & -1.288 \\
\hline Leaf margin dentate & 0.352 & -0.013 & SLA correlated $A$ & -0.357 & 1.431 \\
\hline Leaf color green & 0.796 & -0.102 & Photosynthetic assimilation $(A)$ & 0.615 & -0.017 \\
\hline Leaf color dark green & 1.226 & -0.244 & Transpiration $(E)$ & -0.381 & -1.036 \\
\hline Leaf texture intermediate & -2.886 & 1.905 & Water Use Efficiency (A/E) & -0.241 & -0.471 \\
\hline Leaf texture scabrous & -2.734 & 2.907 & Root Volume & 1.117 & -0.589 \\
\hline${ }^{3}$ Rachis color green & 0.356 & -0.387 & Foliar:Rachis biomass & 0.295 & -0.387 \\
\hline${ }^{3}$ Rachis color yellow & -0.500 & 0.086 & Total Biomass & -1.027 & 2.878 \\
\hline${ }^{3}$ Rachis color red & -0.627 & 0.209 & Sqrt(Shoot:Root + 1) & -1.450 & 1.248 \\
\hline${ }^{3}$ Rachis with viscid hairs & -0.002 & -0.056 & & & \\
\hline${ }^{3}$ Lenticels striated and round & 0.185 & -1.519 & & & \\
\hline${ }^{3}$ Lenticels round & 0.546 & -3.534 & & & \\
\hline${ }^{3}$ Leafcar notched & 1.979 & 1.121 & & & \\
\hline${ }^{3}$ Stem glabrous & 0.094 & 0.740 & & & \\
\hline Proportion of trace & 0.647 & 0.353 & & 0.770 & 0.230 \\
\hline
\end{tabular}

${ }^{1}$ SPAD meter reading of chlorophyll fluorescence. Initial shoot was abbreviated IS.

TABLE 4 | Proportion of $J . \times$ bixbyi Rehd. individuals assigned to the parameter space of Juglans ailantifolia Carr. var. cordiformis, J. cinerea L., and J. nigra L. based on the vegetative or functional adaptive trait discriminant analyses.

\begin{tabular}{lcc}
\hline Parameter space & Adaptive LDA & Vegetative LDA \\
\hline Juglans ailantifolia Carr. var. cordiformis & 0.233 & 0.506 \\
Juglans cinerea L. & $0.287(0.164)$ & 0.210 \\
Intermediate & $0.069(0.014)$ & 0.235 \\
Juglans nigra L. & $0.366(0.233)$ & 0.012 \\
Novel combination & 0.178 & 0.037
\end{tabular}

Intermediate refers to parameter space between J. ailantifolia and J. cinerea 95\% confidence ellipses (CES). Novel combination refers to parameter space not occupied by J. ailantifolia, J. cinerea, or J. nigra CEs. For the adaptive LDA, values do not sum to one due to the overlap of J. cinerea and J. nigra CEs. The overlap influenced J. cinerea, J. nigra, and Intermediate proportions. The value in parenthesis represents the proportion of hybrids assigned to that parameter space only.

two analyses, but the proportion of assignments within each family was highly variable (Table 5). Projections of only hybrids exhibiting initial stem color (red), the trait with the highest loading and corresponding to J. cinerea phenotype, did not all fall within $J$. cinerea parameter space in the functional adaptive trait analysis. Of these 13 individuals four fell within J. cinerea adaptive trait parameter space; four were outside J. ailantifolia, J. cinerea, and J. nigra parameter space; and the remaining five within J. nigra (2), J. ailantifolia (2), and intermediate J. ailantifolia/J. cinerea space (1).

\section{DISCUSSION}

\section{Implications of Hybrid Projections on Hybrid Trajectory}

Hybridization has been described as evolution in action, and it can be thought of in terms of Hardy-Weinberg principles (Anderson and Stebbins, 1954). Hybridization events introduce variability (increase cluster volume in trait space), similar to mutation, while selection acts on variability affecting cluster volume and trajectory. Unequal contributions to future generations by progenitor and hybrid populations skew genetic contributions independent of selection, similar to drift. Roughly equivalent contributions to future generations can result in a highly diverse gene pool that would have potential to evolve under selection pressure. Our example in Juglans demonstrates how discriminant analysis can be used to visualize the current hybrid trajectory based upon individual hybrid responses relative to the progenitor species' responses. Without an assessment of current demography and selection pressures, however, it is not possible to parse out factors associated with hybridization, notably genetic, and demographic swamping (Todesco et al., 2016) that determine trajectory. Independent of the underlying cause(s), the current trajectory informs managers of the variability of current hybrids. Use of discriminant analysis of phenotypes, especially with non-destructive trait sampling, will allow managers to evaluate breeding and planting efforts as indicated 
TABLE 5 | Juglans $\times$ bixbyi Rehd. family breakdown of parameter space assignments based upon the vegetative and adaptive trait discriminant analyses.

\begin{tabular}{lcccc}
\hline Family $^{1}$ & Vegetative & \multicolumn{3}{c}{ Adaptive } \\
\hline 129 & Outside & $2 / 4$ & J. cinerea & $3 / 4$ \\
165 & J. cinerea & $2 / 4$ & J. cinerea & $4 / 4$ \\
780 & J. nigra & $3 / 4$ & J. ailantifolia/Int. & $2 / 4$ \\
781 & J. ailantifolia & $3 / 7$ & J. ailantifolia & $5 / 7$ \\
782 & Outside & $2 / 3^{2}$ & J. cinerea/Int./J. ailantifolia & $1 / 3$ \\
803 & J. ailantifolia & $2 / 4^{2}$ & J. ailantifolia & $4 / 4$ \\
1001 & J. ailantifolia/J. nigra & $1 / 2$ & J. ailantifolia & $2 / 2$ \\
1062 & J. ailantifolia & $2 / 6$ & J. ailantifolia/Int./J. cinerea & $2 / 6$ \\
1093 & J. ailantifolia/Int. & $1 / 3^{2}$ & J. cinerea/J. ailantifolia/Outside & $1 / 3$ \\
701 & Outside & $2 / 2$ & Outside/J. ailantifolia & $1 / 2$ \\
890 & J. ailantifolia/J. nigra & $3 / 6^{3}$ & J. ailantifolia & $4 / 8$ \\
1033 & J. cinerea/J. nigra & $2 / 4$ & J. ailantifolia & $4 / 4$ \\
1061 & J. cinerea/J. nigra & $4 / 9$ & J. ailantifolia/Int. & $4 / 9$ \\
1066 & J. ailantifolia & $3 / 6$ & J. ailantifolia & $4 / 6$ \\
1064 & J. cinerea/Outside & $2 / 8$ & J. ailantifolia & $5 / 8$ \\
1065 & J. cinerea & $4 / 7$ & Int. & $4 / 7$ \\
\hline 1520 & Tabo & 2 for familprovenan & \\
\hline
\end{tabular}

${ }^{1}$ See Table 2 for family provenance. ${ }^{2}$ One individual excluded due to missing data.

${ }^{3}$ Two individuals excluded due to missing data.

in the Wayne and Schaffer (2016) decision tree analysis of hybrids.

Projecting $J \times$ bixbyi hybrids onto the parameter space from the vegetative and functional adaptive discriminant analysis revealed two different trajectories. The vegetative analysis indicated that most hybrids were on Trajectory 1 , introgressing toward J. ailantifolia (Figure 3B; Table 4). As few individuals fell onto parameter space not occupied by J. cinerea, J. ailantifolia, or intermediate to the two, simple removal of Japanese walnut and J. ailantifolia-like hybrids (Allendorf et al., 2001) could shift the pool toward the then demographically more abundant butternut. When projected on the adaptive trait discriminant analysis parameter space, however, hybrids followed no clear pattern (Figure 4B); they were more consistent with Trajectory 4 than Trajectory 1. Many individuals fell outside the progenitors' or the intermediate parameter space, indicating that they represented novel phenotypes (Table 4). Interestingly, the hybrid cluster expanded more in the direction of black walnut (northeast: Figure 4B) than it did to the southeast. This possibly reflects better representation of hybrid phenotype combinations in this region of the parameter space and could indicate that additional outgroups, like Persian walnut (J. regia L.) would reveal even greater variation in hybrids. Trajectory 1 and 4 indicate that the use of hybrids in butternut restoration should be carefully weighed, as the phenotypes of hybrids are widely variable and probably unpredictable, even in uniformly mesic conditions. Assuming that the chosen functional traits adequately describe the autecological differences between butternut and heartnut, the data shows that only $28.7 \%$ of hybrids might match the physiology of $J$. cinerea. On the other hand, $23.3 \%$ of hybrids would match the physiology of J. ailantifolia on those sites, leading to survival in scenarios where butternut might not survive, e.g., flood (Crystal and Jacobs, 2014), and altering the trajectory of hybrids further. Furthermore, the functional variability of the hybrids increases the likelihood they will be able to colonize new areas, potentially those currently occupied by black walnut, as indicated by hybrid occupation of the J. nigra parameter space (Figure 4; Table 4), or become invasive (Ellstrand and Schierenbeck, 2006).

The $J . \times$ bixbyi hybrid swarm in Figure 4 fits with current information regarding hybrid butternut demography. Woeste and Pijut (2009) report that F1 heterosis led to artificial selection of hybrids by homesteaders to serve as nut trees. Increased fitness in the F1 generation has been implicated in the establishment of future hybrid generations (Drake, 2006), as Hoban et al. (2009) found. Furthermore, the majority of these hybrids occur in anthropogenically disturbed habitats (Hoban et al., 2012a), probably due to human mediated transport of F1 individuals (Woeste and Pijut, 2009) and the short dispersal distance (generally $<100 \mathrm{~m}$ ) of butternut seeds from mother trees (Hoban et al., 2012b) in subsequent F2 and backcross generations.

Discrepancies between the two analyses in the shape of the J. ailantifolia, J. cinerea, and J. nigra clusters are expected. The vegetative characters were chosen specifically for their power to distinguish the species. Adaptive traits were not chosen to distinguish among species and there is more variation inherent in quantitative compared to qualitative traits. This is shown by the overlap between J. cinerea and J. nigra clusters in the adaptive trait LDA; nevertheless, distinct clustering among species still occurred. While cluster overlap could indicate that J. cinerea and J. nigra are more related in terms of competition and site preference than heartnut, all seedlings in this study were grown under mesic conditions in which Juglans spp. typically thrive (Goodell, 1984). These taxa would likely respond differentially to drier or wetter conditions (Crystal and Jacobs, 2014), which would result in greater cluster differentiation.

The hybrid swarm effect typically establishes under little or no selection. As the majority of hybrids are found in areas near human habitation (Hoban et al., 2012a), which are usually mesic and favorable to most walnut species (Goodell, 1984), fitness effects from differences in progenitor habitat tolerance (e.g., Crystal and Jacobs, 2014) are limited. Similarly, butternut canker disease is a weak pathogen and takes years to cause mortality (Ostry et al., 1994). As such, increased fitness associated with greater disease resistance (Orchard et al., 1982) is not likely to facilitate rapid introgression of Japanese walnut alleles. The long lifespan of forest trees reduces the probability that small fitness contributions will spread rapidly throughout the population (White et al., 2007). As mature butternuts continue to succumb to age and disease, the effects of the pathogen, which is particularly lethal to seedlings (Tisserat and Kuntz, 1982), may act to select for more disease resistant hybrids that are also likely to contain more Japanese walnut genome. The hybrid swarm, however, has already established, so demographic collapse of butternut does not guarantee that hybrids will introgress toward Japanese walnut. As Allendorf et al. (2001) suggest, all progeny from hybrids are hybrids. Without sufficient numbers of progenitors, hybrids will be unlikely to ever introgress enough of the genome of butternut or Japanese walnut to be considered equivalent to one of the progenitor species in the 
current selection environment (Rhymer and Simberloff, 1996; Rieseberg and Carney, 1998).

Irrespective of trajectory (Figures 3B or 4B), the observation that even hybrids from the same half-sibling progeny varied widely for both trait suites (Table 5) and presented constellations of traits unlike either progenitor indicates that general broadcasting of hybrid trees for use in lieu of butternut should be avoided (Michler et al., 2006). High variability among hybrids in functional adaptive traits indicates that extreme care should be taken in choosing individuals for a resistance breeding program. Based upon recombination and independent assortment, certain resistant trees could contribute high amounts of heartnut genome. Accordingly, for so-called butternut hybrids, a white list of seedlings screened in some fashion before outplanting, is probably most appropriate. Discriminant analysis may prove useful in this regard. Through assessment of functional adaptive traits of butternut and heartnut, the traits most responsible for differences between the taxa could be identified and utilized for hybrid screening.

\section{Use of Discriminant Analysis to Assess Other Unknown Hybrid Gene Pools}

As Paris and Windham (1988) reported in their morphometric analysis of fern taxa, discriminant analysis is effective at identifying hybrids. Their hybrids, however, were morphologically intermediate, similar to results from F1 eucalypt hybrids (Barbour et al., 2007). As demonstrated here, discriminant analysis can be used on known hybrids to help evaluate the trajectory of the current hybrid population. Introgression (Zalapa et al., 2009) and hybrid swarm effects can be revealed with detailed genetic analysis, especially with the advance of sequencing technology to produce the required amount of markers (Boecklen and Howard, 1997; Elshire et al., 2011). Yet, genetic analysis often cannot reveal phenotype, which is ultimately what selection acts upon.

Discriminant analysis provides a relatively quick assessment of the current hybrid trajectory and, through that, historical selection mechanisms. If paired with detailed genetic analysis, it may provide answers to the difficult question commonly raised in management of hybrids: what proportion of one progenitor's DNA indicates that a hybrid can be considered a member of a progenitor species (Allendorf et al., 2001)? It may also assist in demonstrating which portions of the genome are integral to ecological similarity, similar to studying the genomics of adaptation. In order to provide answers to these questions, however, assessment has to occur at an appropriate suite of traits. The selection of traits to include in the analysis ultimately depends on the taxa in question, desired traits, known or hypothesized selective pressures, and the environment that hybrids usually occupy. As such, it is not possible to provide all of the traits necessary for a complete assessment across all taxa, but general guidelines are presented below.

Ecological equivalence plays an important role in evaluating hybrids for conservation, as detailed by Wayne and Schaffer (2016). The assessment of hybrids for traits not directly associated with fitness but related to ecosystem function, e.g., tannins in leaves (Whitham et al., 2006) can be useful for determining the ecological equivalence of hybrids in communities. The analysis of quantitative traits as an indication of the extent of genetic introgression in the offspring of phenotypically distinct progenitors is analogous to the use of neutral genetic markers, but as Howe et al. (2003) show, populations not diverged at neutral markers often are diverged at adaptive traits. The direct assessment of functional traits is therefore critical to determine ecological similarity.

The selection of traits for analysis depends on knowledge of progenitors' ecological function. When a particular trait is known to be essential for functionality, multivariate techniques are not essential for assessing hybrid ecological similarity. This is commonly the case for natural hybrid zones, where discrepancies in adaptive trait variation are suspected due to existing environmental gradients (Campbell and Waser, 2001; Kimball et al., 2008). Discriminant analysis at traits that have no obvious adaptive importance, however, may provide additional information on the overall variability in hybrid phenotypes relative to progenitors. For example, Lilly et al. (2012) evaluated loblolly (Pinus taeda L.) $\times$ shortleaf (P. echinata Mill.) F1 hybrids at several functional traits. They suggested that the hybrid's reduced basal crooking, a trait associated with sprouting following fire and highly expressed in shortleaf pine, maintained the genetic integrity of shortleaf pine under a fire regime. Now that fire is essentially absent from the ecosystem, other traits govern hybrid fitness relative to progenitors. Tauer et al. (2012) report loss of genetic integrity in the demographically reduced shortleaf pine. In this example, discriminant analysis on the traits used in Lilly et al. (2012) could have revealed phenotypic covariance of traits or better explained how F1 hybrids related to progenitors.

Discriminant analysis is most useful when there is little information on progenitor ecological function. It can demonstrate how hybrids relate to progenitors across a wide suite of traits and potentially, what traits distinguish the two progenitors under a particular selection regime. This is especially important for analysis of hybrids between native and exotic congeners, which may have considerable overlap in their ecological function. As demonstrated here, combinations of many factors, not a single trait, defined differences between butternut and Japanese walnut.

Ultimately, fitness is governed by survival and contributions to future generations. Trees in this study were grown under low stress conditions and only chloroplast mutants, which would be less fit in any environment, were removed. As such, no selection occurred, an issue with most hybrid studies (Campbell and Waser, 2001). The growing environment, however, reflected current hybrid conditions. Instituting an environmental selection factor could result in greater separation of the progenitors in a discriminant analysis because of differential response to stress. It may also allow greater visualization of hybrid phenotypes as some transgressive traits are only expressed under certain conditions (Fritz et al., 2006; Ma et al., 2010). If the use of hybrids is essential to rare species conservation (e.g., for the introduction of resistance genes, Michler et al., 2006), identification of differential environmental selection mechanisms is critical to removing 
hybrids that do not replicate the desired progenitors' ecological function. In the above example with loblolly and shortleaf pine hybrids, discriminant analysis at the predefined traits could be used to assess trajectory (and thus similarity) of naturally occurring progeny under the particular selection regimes of the habitat they are found in (i.e., a habitat typically associated with shortleaf or loblolly pine).

This approach to trajectory assessment is most useful for analysis of naturally occurring hybrids or later generation artificial hybrids. It bypasses the need to separate individuals into classes, which are highly variable (Cheng et al., 2011), through genotyping, which is expensive and time consuming. It can only be applied to species that are amenable to growth in a common garden, as environmental variation will lead to phenotypic variation. Multiple common garden tests can be used to plot how the hybrid trajectory will change depending on the selection environment. Gains realized from discriminant analysis are most appreciated in long-lived species (i.e., perennial plants, forest trees, and certain fish species) where direct assessment of fitness through fecundity is exceptionally tedious, and determining ecological similarity for breeding efforts extremely useful (Woeste et al., 1998). For short-lived species (i.e., annual plants, some insects, or other species with rapid generation turnover) where direct assessment of fitness can be measured through reproductive potential, discriminant analysis is not necessary. Clearly, the applicability of this technique needs to be assessed under multiple selection gradients and paired with genetic analysis to determine overall hybrid function.

\section{REFERENCES}

Allendorf, F. W., Leary, R. F., Spruell, P., and Wenburg, J. K. (2001). The problems with hybrids: setting conservation guidelines. Trends Ecol. Evol. 16, 613-622. doi: 10.1016/S0169-5347(01)02290-X

Anderson, E., and Stebbins, G. L. Jr. (1954). Hybridization as an evolutionary stimulus. Evolution 8, 378-388. doi: 10.2307/2405784

Anderson, E., and Thompson, E. (2002). A model-based method for identifying species hybrids using multilocus genetic data. Genetics 160, 1217-1229.

Arnold, M. L., and Martin, N. H. (2010). Hybrid fitness across time and habitats. Trends Ecol. Evol. 25, 530-536. doi: 10.1016/j.tree.2010.06.005

Barbour, R. C., Potts, B. M., and Vaillancourt, R. E. (2007). Gene flow between introduced and native Eucalyptus species: morphological analysis of Tri-species and backcross hybrids involving E-nitens. Silvae Genet. 56, $127-133$.

Bixby, W. G. (1919). The butternut and the Japan walnut. Am. Nut J. 10, 76-83.

Boecklen, W. J., and Howard, D. J. (1997). Genetic analysis of hybrid zones: numbers of markers and power of resolution. Ecology 78, 2611-2616. doi: 10.1890/0012-9658(1997)078[2611:GAOHZN]2.0.CO;2

Bonner, F. T. (2008). "Juglandaceae-Walnut family," in The Woody Plant Seed Manual, eds F. T. Bonner and R. P. Karrfalt (Washington, DC: U.S. Department of Agriculture, Forest Service), 601-606.

Burdett, A. N. (1979). A nondestructive method for measuring the volume of intact plant parts. Can. J. For. Res. 9, 120-122. doi: 10.1139/x79-021

Burgess, K. S., Morgan, M., Deverno, L., and Husband, B. C. (2005). Asymmetrical introgression between two Morus species (M. alba, M. rubra) that differ in abundance. Mol. Ecol. 14, 3471-3483. doi: 10.1111/j.1365-294X.2005.02670.x

Campbell, D. R., and Waser, N. M. (2001). Genotype-by-environment interaction and the fitness of plant hybrids in the wild. Evolution 55, 669-676. doi: 10.1111/ j.0014-3820.2001.tb00802.x

Chen, Z. J. (2010). Molecular mechanisms of polyploidy and hybrid vigor. Trends Plant Sci. 15, 57-71. doi: 10.1016/j.tplants.2009.12.003

\section{AUTHOR CONTRIBUTIONS}

PC designed and installed the experiment, collected and analyzed the data, and co-wrote the paper. NL contributed to data analysis and interpretation, and co-wrote the paper. KW assisted with data interpretation and co-wrote the paper. DJ supervised the research, helped to design the experiment, and co-wrote the paper.

\section{FUNDING}

Funding was provided by the Hardwood Tree Improvement and Regeneration Center at Purdue University.

\section{ACKNOWLEDGMENTS}

We thank Justin Arsenault, Caleb Brown, James Jacobs, Matt Kraushar, Chris Zellers, and Kate Zellers for assistance with experimental design and measurements. James McKenna and Brian Beheler provided seedlings and greenhouse support. Charles Michler reviewed an earlier draft of this manuscript. Mention of a trademark, proprietary product, or vendor does not constitute a guarantee or warranty of the product by the U.S. Department of Agriculture and does not imply its approval to the exclusion of other products or vendors that also may be suitable.

Cheng, D., Vrieling, K., and Klinkhamer, P. G. L. (2011). The effect of hybridization on secondary metabolites and herbivore resistance: implications for the evolution of chemical diversity in plants. Phytochem. Rev. 10, 107-117. doi: 10.1007/s11101-010-9194-9

Cornelissen, J. H. C., Lavorel, S., Garnier, E., Diaz, S., Buchmann, N., Gurvich, D. E., et al. (2003). A handbook of protocols for standardised and easy measurement of plant functional traits worldwide. Aust. J. Bot. 51, 335-380. doi: 10.1071/BT02124

Crystal, P. A., and Jacobs, D. F. (2014). Drought and flood stress tolerance of butternut (Juglans cinerea) and naturally occurring hybrids: implications for restoration. Can. J. For. Res. 44, 1206-1216. doi: 10.1139/cjfr-20140151

Diskin, M., Steiner, K. C., and Hebard, F. V. (2006). Recovery of American Chestnut characteristics following hybridization and backcross breeding to restore blight-ravaged Castanea dentata. Forest Ecology and Management 223, 439-447. doi: 10.1016/j.foreco.2005.12.022

Drake, J. M. (2006). Heterosis, the catapult effect and establishment success of a colonizing bird. Biol. Lett. 2, 304-307. doi: 10.1098/rsbl.2006.0459

Ellstrand, N. C., and Schierenbeck, K. A. (2006). Hybridization as a stimulus for the evolution of invasiveness in plants? Euphytica 148, 35-46. doi: 10.1007/s10681006-5939-3

Elshire, R. J., Glaubitz, J. C., Sun, Q., Poland, J., Kawamoto, K., Buckler, E. S., et al. (2011). A robust, simple genotyping-by-sequencing (GBS) approach for high diversity species. PLoS ONE 6:e19379. doi: 10.1371/journal.pone.0019379

Farlee, L., Woeste, K., Ostry, M., McKenna, J., and Weeks, S. (2010). Identification of Butternuts and Butternut Hybrids. West Lafayette, IN: Purdue University, $1-11$.

Fjellstrom, R. G., and Parfitt, D. E. (1994). Walnut (Juglans spp.) genetic diversity determined by restriction fragment length polymorphisms. Genome 37, 690-700. doi: 10.1139/g94-097

Fox, J., and Weisberg, S. (2011). An $\{R\}$ Companion to Applied Regression, 2nd Edn. Thousand Oaks CA: Sage. 
Fritz, R. S., Hochwender, C. G., Albrectsen, B. R., and Czesak, M. E. (2006). Fitness and genetic architecture of parent and hybrid willows in common gardens. Evolution 60, 1215-1227. doi: 10.1554/05-343.1

Furnier, G. R., Stolz, A. M., Mustaphi, R. M., and Ostry, M. E. (1999). Genetic evidence that butternut canker was recently introduced into North America. Can. J. Bot. 77, 783-785. doi: 10.1139/b99-013

Gauthier, M.-M., Zellers, K. E., Löf, M., and Jacobs, D. F. (2013). Inter- and intraspecific competitiveness of plantation-grown American chestnut (Castanea dentata). For. Ecol. Manage. 291, 289-299.

Goodell, E. (1984). Walnuts for the Northeast. Arnoldia 44, 3-19.

Grossnickle, S. (2012). Why seedlings survive: influence of plant attributes. New For. 43, 711-738. doi: 10.1007/s11056-012-9336-6

Hoban, S. M., McCleary, T. S., Schlarbaum, S. E., Anagnostakis, S. L., and RomeroSeverson, J. (2012a). Human-impacted landscapes facilitate hybridization between a native and an introduced tree. Evol. Appl. 5, 720-731. doi: 10.1111/j. 1752-4571.2012.00250.x

Hoban, S. M., McCleary, T. S., Schlarbaum, S. E., and Romero-Severson, J. (2009). Geographically extensive hybridization between the forest trees American butternut and Japanese walnut. Biol. Lett. 5, 324-327. doi: 10.1098/rsbl.2009. 0031

Hoban, S. M., Schlarbaum, S., Brosi, S., and Romero-Severson, J. (2012b). A rare case of natural regeneration in butternut, a threatened forest tree, is parent and space limited. Conserv. Genet. 13, 1447-1457. doi: 10.1007/s10592-0120386-2

Howe, G. T., Aitken, S. N., Neale, D. B., Jermstad, K. D., Wheeler, N. C., and Chen, T. H. H. (2003). From genotype to phenotype: unraveling the complexities of cold adaptation in forest trees. Can. J. Bot. 81, 1247-1266. doi: 10.1139/b03-141

IPGRI (1994). Descriptors for Walnut: (Juglans spp.). Rome: International Plant Genetic Resources Institute.

Kimball, S., Campbell, D. R., and Lessin, C. (2008). Differential performance of reciprocal hybrids in multiple environments. J. Ecol. 96, 1306-1318. doi: 10. 1111/j.1365-2745.2008.01432.x

Kimura, M., Seiwa, K., Suyama, Y., and Ueno, N. (2003). Flowering system of heterodichogamous Juglans ailanthifolia. Plant Species Biol. 18, 75-84. doi: 10. 1111/j.1442-1984.2003.00088.x

Legendre, P., and Legendre, L. (2003). Numerical Ecology: Second English Edition. Amsterdam: Elsevier Science.

Levin, D. A., Francisco-Ortega, J., and Jansen, R. K. (1996). Hybridization and the extinction of rare plant species. Conserv. Biol. 10, 10-16. doi: 10.1046/j.15231739.1996.10010010.x

Lilly, C. J., Will, R. E., and Tauer, C. G. (2012). Physiological and morphological attributes of shortleaf $\times$ loblolly pine F1 hybrid seedlings: is there an advantage to being a hybrid? Can. J. For. Res. 42, 238-246. doi: 10.1139/ x11-180

Ma, F., Zhao, C. M., Milne, R., Ji, M. F., Chen, L. T., and Liu, J. Q. (2010). Enhanced drought-tolerance in the homoploid hybrid species Pinus densata: implication for its habitat divergence from two progenitors. New Phytol. 185, 204-216. doi: 10.1111/j.1469-8137.2009.03037.x

Mayer, M. S., and Mesler, M. R. (1993). Morphometric evidence of hybrid swarms in mixed populations of Polystichum munitum and P. imbricans (Dryopteridaceae). Syst. Bot. 18, 248-260. doi: 10.2307/2419401

Michler, C. H., Pijut, P. M., Jacobs, D. F., Meilan, R., Woeste, K. E., and Ostry, M. E. (2006). Improving disease resistance of butternut (Juglans cinerea), a threatened fine hardwood: a case for single-tree selection through genetic improvement and deployment. Tree Physiol. 26, 121-128. doi: 10.1093/treephys/ 26.1.121

Orchard, L. P., Kuntz, J. E., and Kessler, K. J. (1982). Reactions of Juglans species to butternut canker and implications for disease resistance. Black Walnut for the Future: General Technical Report NC-74. St. Paul, MN: U.S. Department of Agriculture Forest Service. North Central Forest Experiment Station.

Ostry, M. E., Mielke, M. E., and Skilling, D. D. (1994). Butternut-Strategies for Managing a Threatened Tree. General Technical Report NC-165. St. Paul, MN: U.S. Department of Agriculture Forest Service. North Central Forest Experimental Station.
Paris, C. A., and Windham, M. D. (1988). A biosystematic investigation of the Adiantum pedatum complex in eastern North America. Syst. Bot. 13, 240-255. doi: $10.3732 /$ ajb.1100125

R Core Team (2012). R: A Language and Environment for Statistical Computing. Vienna: R Foundation for Statistical Computing.

Rhymer, J. M., and Simberloff, D. (1996). Extinction by hybridization and introgression. Annu. Rev. Ecol. Syst. 27, 83-109. doi: 10.1146/annurev. ecolsys.27.1.83

Rieseberg, L. H., and Carney, S. E. (1998). Plant hybridization. New Phytol. 140, 599-624. doi: 10.1046/j.1469-8137.1998.00315.x

Seiwa, K. (2000). Effects of seed size and emergence time on tree seedling establishment: importance of developmental constraints. Oecologia 123, 208215. doi: 10.1007/s004420051007

Soltis, P. S., and Soltis, D. E. (2009). The role of hybridization in plant speciation. Annu. Rev. Plant Biol. 60, 561-588. doi: 10.1146/annurev. arplant.043008.092039

Stout, A. B. (1928). Dichogamy in flowering plants. Bull. Torrey Bot. Club 55, 141-153. doi: $10.2307 / 2480605$

Tauer, C. G., Stewart, J. F., Will, R. E., Lilly, C. J., Guldin, J. M., and Nelson, C. D. (2012). Hybridization leads to loss of genetic integrity in shortleaf pine: unexpected consequences of pine management and fire suppression. J. For. 110, 216-224. doi: 10.5849/jof.11-044

Tisserat, N. A., and Kuntz, J. E. (1982). "Epidemiology of butternut canker," in Proceedings of the Symposium on Black Walnut for the Future. General Technical Report NC-74, (St. Paul MN: USDA Forest Service. North Central Experiment Station).

Todesco, M., Pascuai, M. A., Owens, G. L., Ostevik, K. L., Moyers, B. T., Hubner, S., et al. (2016). Hybridization and extinction. Evol. Appl. 9, 892-908. doi: 10.1111/ eva.12367

Venables, W. N., and Ripley, B. D. (2002). Modern Applied Statistics with S, 4th Edn. New York, NY: Springer.

Wayne, R. K., and Schaffer, H. B. (2016). Hybridization and endangered species protection in the molecular era. Mol. Ecol. 25, 2680-2689. doi: 10.1111/mec. 13642

White, T. L., Adams, W. T., and Neale, D. B. (2007). Forest Genetics. Cambridge, MA: CABI.

Whitham, T. G., Bailey, J. K., Schweitzer, J. A., Schuster, S. M., Banger, R. K., LeRoy, C. J., et al. (2006). A framework for community and ecosystem genetics: from genes to ecosystems. Nat. Rev. Genet. 7, 510-527. doi: 10.1038/nrg1877

Wilson, B. C., and Jacobs, D. F. (2006). Quality assessment of temperate zone deciduous hardwood seedlings. New For. 31, 417-433. doi: 10.1007/s11056005-0878-8

Woeste, E., Jacobs, D. F., and McKenna, J. R. (2011). Half-sib seed source and nursery sowing density affect black walnut (Juglans nigra) growth after 5 years. New For. 41, 235-245. doi: 10.1007/s11056-010-9224-x

Woeste, K., McGranahan, G., and Bernatzky, R. (1998). Low correlation between genomic and morphological introgression estimates in a walnut backcross. J. Am. Soc. Hortic. Sci. 123, 258-263.

Woeste, K., and Pijut, P. M. (2009). The peril and potential of butternut. Arnoldia $66,2-12$.

Zalapa, J. E., Brunet, J., and Guries, R. P. (2009). Patterns of hybridization and introgression between invasive Ulmus pumila (Ulmaceae) and native U. rubra. Am. J. Bot. 96, 1116-1128. doi: 10.3732/ajb.0800334

Conflict of Interest Statement: The authors declare that the research was conducted in the absence of any commercial or financial relationships that could be construed as a potential conflict of interest.

Copyright (c) 2016 Crystal, Lichti, Woeste and Jacobs. This is an open-access article distributed under the terms of the Creative Commons Attribution License (CC BY). The use, distribution or reproduction in other forums is permitted, provided the original author(s) or licensor are credited and that the original publication in this journal is cited, in accordance with accepted academic practice. No use, distribution or reproduction is permitted which does not comply with these terms. 